\title{
No evidence of increased risk of malignancies in patients with diabetes treated with insulin detemir: a meta-analysis
}

\author{
A. Dejgaard • H. Lynggaard • J. Råstam • \\ M. Krogsgaard Thomsen
}

Received: 31 August 2009 / Accepted: 23 September 2009 / Published online: 17 October 2009

(C) Springer-Verlag 2009

\begin{abstract}
Aims/hypothesis Recent epidemiological studies suggest that treatment with insulin glargine (A21Gly,B31Arg, B32Arg human insulin) may promote cancer growth. The present meta-analysis was performed to assess the risk of cancer during treatment with insulin detemir (B29Lys $(\varepsilon-$ tetradecanoyl),desB30 human insulin), another long-acting insulin analogue.

Methods This meta-analysis was performed in a population of 8,693 patients with type 1 or type 2 diabetes, who were included in Novo Nordisk-sponsored, randomised and controlled diabetes trials of at least 12 weeks in duration that compared insulin detemir with NPH insulin or insulin glargine. In a blinded manner, the adverse events with suspected treatment-emergent malignant tumours were obtained from these studies under three system-organ classes: 'Neoplasms benign, malignant and unspecified (including cysts and polyps)', 'Neoplasm' and 'Surgical and medical procedures'. Conditional ORs were estimated applying both the MantelHaenzel and Peto methods to ensure robustness of results.

Results Separate analyses were performed for trials comparing insulin detemir with NPH insulin and insulin detemir with insulin glargine. In the first analysis, 16 studies were included with a total of 3,983 patients treated with insulin detemir and 2,661 patients treated with NPH insulin. In the second analysis, five studies were included with a total of 1,219 patients treated with insulin detemir and 830 patients treated with insulin glargine. The estimated OR for a cancer diagnosis between NPH insulin and insulin detemir was
\end{abstract}

A. Dejgaard $(\bowtie) \cdot$ H. Lynggaard $\cdot$ J. Råstam •

M. Krogsgaard Thomsen

Novo Nordisk,

Novo Alle 1,

2880 Bagsvaerd, Denmark

e-mail: ade@novonordisk.com statistically significantly $>1$, with the ratio favouring insulin detemir. There was a more than twofold higher cancer occurrence in the NPH insulin-treated population. For the insulin detemir comparison with insulin glargine, there was a non-significant difference in ORs in favour of insulin detemir.

Conclusions/interpretation In these randomised controlled diabetes trials, patients treated with insulin detemir had a lower or similar occurrence of a cancer diagnosis compared with patients treated with NPH insulin or insulin glargine, respectively.

Keywords Cancer - Diabetes mellitus · Insulin detemir . Insulin glargine $\cdot$ Malignancy $\cdot$ Meta-analysis $\cdot$ Neoplasm . NPH insulin
Abbreviations
IPD Individual patient data
MH Mantel-Haenszel
RCT Randomised clinical trial

\section{Introduction}

Recently, four retrospective observational epidemiological studies were published in Diabetologia, in a concerted effort to evaluate whether insulin glargine (A21Gly, B31Arg,B32Arg human insulin) promotes growth of certain tumours [1-4]. As stated in an accompanying Editorial, the data were not conclusive and deserve careful interpretation because of inherent methodological limitations, including the relatively short follow-up period, suboptimal matching of the investigational groups and certain limitations regarding the information available in the 
databases used for the analyses [5]. However, the European Medicines Agency, the Food and Drug Administration, the European Association of the Study of Diabetes, and the American Association of Clinical Endocrinology are in agreement that the concerns raised by these studies require further in-depth evaluation before conclusions can be made.

There is epidemiological evidence that diabetes is an independent predictor of cancer of the breast, colon, bladder, liver, pancreas and endometrium [6,7]. However, clinical data on the relationship between risk of cancer and insulin treatment are sparse. Epidemiological studies have indicated that insulin itself might contribute to increased tumour growth $[3,6,8]$. Some investigators have speculated that this is related to an insulin-mediated increase in IGF-I receptor activity. The challenges in the conduct of studies assessing the role of insulin in propagating cancer are many, and include issues such as confounding by indication, as type 2 diabetes patients treated with insulin often have a more progressed disease than patients controlled on oral agents. In addition, these patients treated with insulin are more insulin-resistant and obese, and are often older than their counterparts treated with oral hypoglycaemic agents.

Until very recently, there were no clinical studies addressing whether insulin analogues promote the growth of malignant tumours. However, as discussed in the recent Editorial in this journal [5], almost two decades ago, Novo Nordisk terminated the clinical development programme for a fast-acting insulin analogue known as X10 because of dose-dependent formation of mammary adenocarcinomas in female rats [8]. The molecular basis for these findings is thought to be a sixfold increase in the affinity for the IGF-I receptor because of the substitution of the histidine residue in position B10 [9]. Another contributing factor may be the slow rate of X10 dissociation from the insulin receptor compared with human insulin [9].

IGF-I has been implicated as playing an important role in the progression and, potentially, in the development of human cancers [10]. Indeed, the IGF-I receptor has been demonstrated on a wide range of malignant cell types [10]. Subsequent studies have shown that increased mitogenicity appears to be associated with mitogen-activated protein kinase pathway activation via the IGF-I receptor [11]. Furthermore, epidemiological data have revealed that patients with high levels of IGF-I have a near-doubling in the risk of developing cancer, compared with those with IGF-I levels in the low end of the normal range. Finally, based on the expected role of IGF-I in tumour growth, antiIGF-I receptor antibodies have been explored for the treatment of certain cancers [12].

Ever since the above-mentioned relationship between altered receptor binding and kinetics were found for insulin X10, Novo Nordisk has, as primary selection criteria within insulin research, required that the ratio between IGF-I receptor binding affinity and insulin receptor binding affinity should be similar to or lower than that of human insulin. In this regard, both insulin detemir (B29Lys $(\varepsilon-$ tetradecanoyl),desB30 human insulin) (Levemir) and insulin aspart (B28Asp human insulin) (Novo Rapid, Novolog, Novo Mix and Novo Log Mix) have a balance between binding affinities to the insulin receptor and the IGF-I receptor that is similar to human insulin $[9,13]$.

Insulin detemir was recently introduced as an albuminbound, once-daily basal insulin that has no amino acid substitutions in the insulin molecule, but a deletion in the B30 position and addition of a natural $\mathrm{C} 14$ fatty acid, myristic acid, in position B29. Since the regulatory approval of insulin detemir, no cancer signal has been observed, based on rigorous pharmaco-vigilance monitoring.

The recent publications of a potential relationship between insulin glargine and cancer did not raise any concerns regarding the rapid acting and pre-mixed insulin analogues. However, in spite of the high degree of molecular safety of insulin detemir in published in vitro studies $[9,11]$, it is obvious to ask the question whether clinical use of this long-acting analogue has any influence on the development of cancer. In this paper we present an up-to-date meta-analysis designed to characterise the risk of cancer using insulin detemir based on data that have emerged from randomised controlled clinical trials sponsored by Novo Nordisk which compared insulin detemir with either NPH insulin or insulin glargine.

\section{Methods}

This study is an individual patient data (IPD) meta-analysis of cancer incidence in Novo Nordisk-sponsored randomised clinical trials (RCTs). Accordingly, the analysis is not based on a classic literature search as known from a systematic review. The IPD meta-analysis allows doing more in-depth analyses, and exploring any heterogeneity in more detail.

The analysis follows the recommendations by Whitehead [14] and is in accordance with relevant issues highlighted by QUOROM [15] and CPMP [16], bearing in mind that the QUOROM guidelines are primarily aimed at literaturebased meta-analyses and the CPMP guideline is mainly relevant for prospective meta-analyses.

Standard criteria for inclusion in the meta-analysis include good clinical practice compliance (to limit heterogeneity and ensure quality of data). All trials are randomised and open-labelled.

For the purposes of this meta-analysis, the defined study population should not limit the scope of the conclusions but, at the same time, they should not lead to intractable heterogeneity. For this reason studies in children were excluded from the meta-analysis. 
Table 1 Baseline demographics and insulin exposure

\begin{tabular}{|c|c|c|c|c|}
\hline \multirow[t]{2}{*}{ Variable } & \multicolumn{2}{|l|}{$\mathrm{NPH}$ insulin trials } & \multicolumn{2}{|c|}{ Insulin glargine trials } \\
\hline & Insulin detemir & NPH insulin & Insulin detemir & Insulin glargine \\
\hline Patients $(n)$ & 3,983 & 2,661 & 1,219 & 830 \\
\hline Age, years (SD) & $48.8(15.1)$ & $49.7(14.9)$ & $51.6(13.9)$ & $51.9(13.9)$ \\
\hline Type 1 diabetes, $n(\%)$ & $2,065(51.8)$ & $1,244(46.7)$ & $460(37.7)$ & $303(36.5)$ \\
\hline Type 2 diabetes, $n(\%)$ & $1,918(48.2)$ & $1,417(53.3)$ & $759(62.3)$ & $527(63.5)$ \\
\hline Diabetes duration, years (SD) & $13.6(9.4)$ & $13.5(9.0)$ & $13.7(9.6)$ & $12.9(8.8)$ \\
\hline BMI, $\mathrm{kg} / \mathrm{m}^{2}(\mathrm{SD})$ & $26.8(4.8)$ & $26.9(4.8)$ & $29.5(5.2)$ & $29.4(5.1)$ \\
\hline $\mathrm{HbA}_{1 \mathrm{c}}, \%(\mathrm{SD})$ & $8.4(1.2)$ & $8.4(1.2)$ & $8.5(1.0)$ & $8.6(1.0)$ \\
\hline Sex (\% female) & 46 & 44 & 44 & 44 \\
\hline Total exposure (years) & 2,252 & 1,420 & 917 & 628 \\
\hline Median exposure, weeks (range) & $24.0(0.1-114.6)$ & $23.9(0.1-107.9)$ & $51.0(0.1-64.1)$ & $51.1(0.1-57.1)$ \\
\hline
\end{tabular}

The following criteria are applied to the RCTs for inclusion into the analysis: (1) randomised controlled trials in patients with type 1 or type 2 diabetes; (2) insulin detemir was used in one of the treatment arms; (3) NPH insulin and insulin glargine should be the comparator; (4) Novo Nordisk sponsored the trial, i.e. IPD should be available; (5) the trial had a duration of at least 12 weeks; and (6) the commercial formulation of insulin detemir was used.

Heterogeneity is probably limited in this meta-analysis as patient selection criteria across the studies are sufficiently similar to allow inferences applicable to a definable patient population. However, heterogeneity was formally tested by Cochran's $Q$ and quantified by Higgin's $I^{2}[17]$.

The safety population used for the analysis consisted of all randomised patients who had been exposed to at least one dose of the trial treatment. From databases on all adverse events from the included studies, we obtained a list with potential events reported under three system-organ classes: 'Neoplasms benign, malignant and unspecified (including cysts and polyps)', 'Neoplasm' and 'Surgical and medical procedures'. In a blinded manner, suspected treatment-emergent malignant tumours were identified and included in the present analysis. Four patients each had two events, but from the description these events appear to have been related to the same diagnosis. Therefore, they only accounted for one event each in the analyses. It was not possible to decide for two treatment-emergent neoplasms if they were malignant or not. Both these events were included in the analyses.

Owing to the relatively small patient numbers in the data set, we applied different statistical methods to test for any differences and to ensure robustness of the results.

Thus, the following statistical tests were applied: the Peto OR method [18], and the Mantel-Haenszel (MH)
Table 2 Numbers and organ of origin of included tumours

${ }^{\text {a }}$ Number of events

${ }^{\mathrm{b}}$ Event rate/100 exposure-years

\begin{tabular}{|c|c|c|c|c|c|c|c|c|}
\hline \multirow[t]{3}{*}{ Malignant neoplasms } & \multicolumn{4}{|c|}{$\mathrm{NPH}$ insulin trials } & \multicolumn{4}{|c|}{ Insulin glargine trials } \\
\hline & \multicolumn{2}{|c|}{ Insulin detemir } & \multicolumn{2}{|c|}{$\mathrm{NPH}$ insulin } & \multicolumn{2}{|c|}{ Insulin detemir } & \multicolumn{2}{|c|}{ Insulin glargine } \\
\hline & $n^{\mathrm{a}}$ & Rate $^{\mathrm{b}}$ & $n^{\mathrm{a}}$ & Rate $^{b}$ & $n^{\mathrm{a}}$ & Rate $^{b}$ & $n^{\mathrm{a}}$ & Rate $^{\mathrm{b}}$ \\
\hline Total & 8 & 0.36 & 13 & 0.92 & 8 & 0.87 & 8 & 1.27 \\
\hline Breast & 1 & 0.04 & - & - & 1 & 0.11 & 3 & 0.48 \\
\hline Bladder & - & - & - & - & 2 & 0.22 & - & - \\
\hline Lymph nodes & 1 & 0.04 & 1 & 0.07 & - & - & - & - \\
\hline Skin & 2 & 0.09 & 2 & 0.14 & 2 & 0.22 & 1 & 0.16 \\
\hline Colon & - & - & - & - & & & 1 & 0.16 \\
\hline Lung & 1 & 0.04 & 3 & 0.21 & 1 & 0.11 & 2 & 0.32 \\
\hline Lung metastasis & 1 & 0.04 & - & - & - & 0 & - & - \\
\hline Prostate gland & - & - & 3 & 0.21 & 1 & 0.11 & - & - \\
\hline Pharynx & 1 & 0.04 & - & - & - & - & - & - \\
\hline Pancreas & 1 & 0.04 & 4 & 0.28 & 1 & 0.11 & 1 & 0.16 \\
\hline
\end{tabular}


method [19]. The former is recommended in Bradburn et al. [20] and the latter is recommended by the Cochrane Collaboration for analysis of rare events [21]. We calculated a crude overall OR estimate and the Peto and MH OR estimates stratified by trial.

In order to investigate the robustness of the results, additional analyses were made by stratifying according to trial length ( $<26$ weeks, $26-52$ weeks, $>52$ weeks), basal insulin dose at the end of the trial $([\mathrm{U} / \mathrm{kg}] \times 100)$ quartiles $(0-25,25-38,38-57,>57)$, type of diabetes (type 1 and type 2) and use of regimen (basal-bolus or basal insulin only [ \pm oral hypoglycaemic agents]). In the case of a missing end-of-trial dose, the last-observation-carried-forward method was applied.

Because of the limited size of the data set, no further refined analyses such as insulin dose-dependency were thought to be appropriate.

\section{Results}

Out of a total of 95 company-sponsored randomised controlled insulin detemir trials identified in Novo Nordisk databases, 21 qualified for the meta-analysis according to the defined criteria. The following 74 clinical trials were excluded: pharmaco-kinetic and/or pharmaco-dynamic studies $(n=42)$, studies of $<3$ months in duration $(n=5)$, studies in children $(n=6)$, studies with non-marketed formulations $(n=7)$ or irrelevant comparator $(n=9)$, ongoing studies $(n=4)$ and one exploratory study.

Table 3 Analysis results for NPH insulin trials

\begin{tabular}{lllll}
\hline $\begin{array}{l}\text { Stratification/ } \\
\text { method }\end{array}$ & OR $(95 \% \mathrm{CI})$ & $p$ value & $\begin{array}{l}\text { Cochran's } \\
Q(p \text { value })\end{array}$ & $\begin{array}{l}\text { Higgin's } \\
I^{2}\end{array}$ \\
\hline $\begin{array}{l}\text { None/crude } \\
\text { Trial }\end{array}$ & $2.44(1.01-5.89)$ & 0.048 & & \\
$\quad$ MH & $2.53(1.02-6.28)$ & 0.045 & & \\
$\quad$ Peto & $2.53(1.04-6.15)$ & 0.040 & 0.885 & 0 \\
Trial duration & & & & \\
$\quad$ MH & $2.49(1.02-6.08)$ & 0.045 & & \\
$\quad$ Peto & $2.50(1.35-4.64)$ & 0.004 & 0.408 & 0 \\
Insulin dose & & & & \\
MH & $2.50(1.03-6.07)$ & 0.042 & & \\
$\quad$ Peto & $2.53(1.36-4.71)$ & 0.003 & 0.261 & 24.0 \\
Diabetes type & & & & \\
MH & $2.35(0.97-5.70)$ & 0.058 & & \\
$\quad$ Peto & $2.43(1.31-4.51)$ & 0.005 & 0.894 & 0 \\
Insulin regimen & & & & \\
MH & $2.43(1.00-5.87)$ & 0.049 & & \\
Peto & $2.48(1.34-4.60)$ & 0.004 & 0.613 & 0 \\
\hline
\end{tabular}

Table 4 Analysis results for insulin glargine trials

\begin{tabular}{lllll}
\hline $\begin{array}{l}\text { Stratification/ } \\
\text { method }\end{array}$ & OR $(95 \% \mathrm{CI})$ & $p$ value & $\begin{array}{l}\text { Cochran's } \\
Q(p \text { value })\end{array}$ & $\begin{array}{l}\text { Higgin's } \\
I^{2}\end{array}$ \\
\hline $\begin{array}{l}\text { None/crude } \\
\text { Trial }\end{array}$ & $1.47(0.55-3.94)$ & 0.440 & & \\
$\quad$ MH & $1.32(0.51-3.43)$ & 0.566 & & \\
$\quad$ Peto & $1.36(0.50-3.74)$ & 0.546 & 0.052 & 57.4 \\
Trial duration & & & & \\
$\quad$ MH & $1.53(0.58-4.06)$ & 0.395 & & \\
$\quad$ Peto & $1.52(0.75-3.10)$ & 0.246 & 0.452 & 0 \\
Insulin dose & $1.24(0.46-3.30)$ & 0.672 & & \\
$\quad$ MH & $1.36(0.67-2.78)$ & 0.390 & 0.370 & 6.5 \\
$\quad$ Peto & & & & \\
Diabetes type & & & \\
$\quad$ MH & $1.46(0.55-3.90)$ & 0.452 & & \\
$\quad$ Peto & $1.48(0.73-3.00)$ & 0.278 & 0.784 & 0 \\
Insulin regimen & & & & \\
$\quad$ MH & $1.30(0.49-3.42)$ & 0.598 & & \\
Peto & $1.40(0.69-2.84)$ & 0.351 & 0.282 & \\
\hline
\end{tabular}

Sixteen of the included trials had NPH insulin as comparator treatment and five trials had insulin glargine as comparator treatment. Nine of the included trials were in patients with type 1 diabetes, 11 were in type 2 diabetes patients and one study included both type 1 and type 2 diabetes patients. Characteristics of the study groups and patient demographics overall are shown in Table 1. Treatment duration was generally longer in trials comparing insulin detemir with insulin glargine, compared with trials where NPH insulin was the comparator. Furthermore patients were more often affected by type 1 diabetes than type 2 diabetes in trials with NPH insulin as comparator, which was the opposite for patients in the insulin glargine comparison trials. Otherwise the patient demographics were comparable across trials.

Based on the total number of malignant tumours that were included in the two analyses of reported adverse

Table 5 Distribution of events by dose quartile $([\mathrm{U} / \mathrm{kg}] \times 100)$ and treatment group

\begin{tabular}{lccccc}
\hline Dose & \multicolumn{2}{l}{ NPH insulin trials } & & \multicolumn{2}{l}{ Insulin glargine trials } \\
\cline { 2 - 3 } \cline { 5 - 6 } & $\begin{array}{l}\text { Insulin } \\
\text { detemir }\end{array}$ & $\begin{array}{l}\text { NPH } \\
\text { insulin }\end{array}$ & & $\begin{array}{l}\text { Insulin } \\
\text { detemir }\end{array}$ & $\begin{array}{l}\text { Insulin } \\
\text { glargine }\end{array}$ \\
\hline Total & 8 & 13 & & 8 & 8 \\
Quartile & & & & & \\
$0-25$ & 3 & 4 & & 0 & 2 \\
$25-38$ & 0 & 5 & & 3 & 2 \\
$38-57$ & 3 & 1 & & 4 & 2 \\
$>57$ & 2 & 3 & & 1 & 2 \\
\hline
\end{tabular}


events during the trials, the organs related to the cancer diagnosis are listed in Table 2.

Table 3 provides the results of the analysis for NPH insulin comparator trials. No evidence of heterogeneity was seen. All estimated ORs were $>2$, implying higher odds for having a cancer diagnosis in the NPH insulin-treated group compared with the insulin detemir-treated group. The estimated ORs were significantly $>1$ in favour of insulin detemir.

Table 4 shows the results from the insulin glargine comparator trials. A moderate degree of heterogeneity was seen between trials but no heterogeneity was seen for the remaining groupings. Thus, the estimated OR across trials should be interpreted with caution. However, comparing the estimated OR across trials with the remaining estimated ORs indicated consistent results. The estimated ORs were all $>1$, suggesting higher odds for having an event in the insulin glargine-treated group compared with the insulin detemir-treated group. However, in this case the differences were not statistically significant.

The meta-analysis revealed that there was no clear pattern regarding distribution of events across the four insulin dose quartiles and treatment groups (Table 5). This was true for trials with both NPH insulin and insulin glargine as comparator. In addition we found no evidence for a difference in ORs between type 1 and type 2 diabetes or between different insulin regimen (Tables 3 and 4).

\section{Discussion}

Even though the meta-analysis described in this report is based on a limited data set, we conclude from this metaanalysis of randomised, controlled insulin detemir trials that there is no evidence of a signal of any increased cancer risk in patients treated with insulin detemir compared with either NPH insulin or insulin glargine. In contrast, we found significantly lower odds for having a cancer diagnosis in the detemir group compared with the NPH insulin group.

The incidence rate of cancer in this meta-analysis is small for all insulin treatment groups. In part, this is probably because of the inclusion and exclusion criteria applied, which would be predicted to reduce the risk of malignancy. This is typical of the trial populations in RCTs that provide the basis for regulatory drug approval. Furthermore, the numbers are low, owing to the relatively short follow-up period in all of the trials. Because of both the low number of cancer diagnoses, and the multitude of organs involved, it is inappropriate to perform sub-analysis of the topography of the reported tumours. Furthermore, it should be mentioned that post-trial follow-up has not been performed, since the trials were not designed to assess the risk of cancer.
In summary, it is not possible to definitively draw conclusions on the risk of cancer promotion by insulin analogues based on the data presented in this analysis. However, the meta-analysis adds new information to the ongoing debate relating to the clinical safety of basal insulin analogue treatment. We are reassured, based on the existing in vitro findings related to IGF-I receptor binding, insulin receptor dissociation characteristics and clinical trial data, that insulin detemir does not appear to increase the incidence of cancer when compared with treatment with other long-acting insulin preparations.

Duality of interest All authors of this article are employees of Novo Nordisk.

\section{References}

1. Hemkens LG, Grouven U, Bender R et al (2009) Risk of malignancies in patients with diabetes treated with human insulin or insulin analogues: a cohort study. Diabetologia 52:1732-1744

2. Jonasson JM, Ljung M, Talbäck M et al (2009) Insulin glargine use and short-term incidence of malignancies - a populationbased follow-up study in Sweden. Diabetologia 52:1745-1754

3. Currie CJ, Poole CD, Gale EAM (2009) The influence of glucoselowering therapies on cancer risk in type 2 diabetes. Diabetologia 52:1766-1777

4. Colhoun HM, SDRN Epidemiology Group (2009) Use of insulin glargine and cancer incidence in Scotland: a study from the Scottish Diabetes Research Network Epidemiology. Diabetologia 52:1755-1765 Erratum doi:10.1007/s00125-009-1453-1

5. Smith U, Gale EAM (2009) Does diabetes therapy influence the risk of cancer? Diabetologia 52:1699-1708

6. Coughlin SS, Calle EE, Teras LR, Petrelli J, Thun MJ (2004) Diabetes mellitus as a predictor of cancer mortality in a large cohort of US adults. Am J Epidemiol 159:1160-1167

7. Wideroff L, Gridley G, Mellemkjaer L et al (1997) Cancer incidence in a population-based cohort of patients hospitalized with diabetes mellitus in Denmark. J Natl Cancer Inst 89:1360 1365

8. Boyd DB (2003) Insulin and cancer. Integr Cancer Ther 2:315-329

9. Kurtzhals P, Schaeffer 1, Sørensen A et al (2000) Correlations of receptor binding and metabolic and mitogenic potencies of insulin analogs designed for clinical use. Diabetes 49:999-1005

10. Pollak MN, Schernhammer ES, Hankinson SE (2004) Insulin-like growth factors and neoplasia. Nat Rev Cancer 4:505-518

11. Shukla A, Grisourd J, Ehemann V et al (2009) Analysis of signalling pathways related to cell proliferation stimulated by insulin analogs in human mammary epithelial cell lines. Endocr Relat Cancer 16:429-441

12. Yee D (2001) Are the insulin-like growth factors relevant to cancer. Growth Horm IGF Res 11:339-345

13. FDA Levemir pharmacology review (2005) Available from www.accessdata.fda.gov/drugsatfda_docs/nda/2005/021-536_ LevemirTOC.cfm, accessed 30 September 2009

14. Whitehead A (2002) Meta-analysis of controlled clinical trials. Wiley, Chichester

15. Moher D, Cook DJ, Eastwood S, Olkin I, Rennie D, Stroup DF (1999) Improving the quality of reports of meta-analyses of randomised controlled trials: the QUOROM statement. Quality of reporting of meta-analyses. Lancet 354:1896-1900 
16. The European Agency for the Evaluation of the Medicinal Products: Evaluation of medicines for human use. Committee for Proprietary Medicinal Produces (CPMP). Points to consider on validity and interpretation of meta-analyses, and one pivotal study (2000) Available from www.emea.europa.eu/pdfs/human/ewp/ 233099den.pdf, accessed 30 September 2009

17. Higgins JPT, Thompson SG, Deeks JJ, Altman DG (2003) Measuring inconsistency in meta-analyses. BMJ 327:557-560

18. Peto R (1987) Why do we need systematic overviews of randomised trials? Stat Med 6:233-240
19. Yusuf S, Peto R, Lewis J, Colins R, Sleight P (1985) Betablockade during and after myocardial infarction: an overview of the randomized trials. Prog Cardiovasc Dis 27:335-371

20. Bradburn MJ, Deeks JJ, Berlin JA, Localio AR (2007) Much ado about nothing: a comparison of the performance of meta-analytic methods with rare events. Stat Med 26:53-77

21. The Cochrane policy manual: The Cochrane Collaboration. The Cochrane policy manual 2009, issue 3 (updated 11 May 2009) (2009) Available from http://Cochrane.org/admin/The_Cochrane Policy Manual 20110509.pdf, accessed 30 September 2009 